\title{
The application of prostate specific membrane antigen in CART-cell therapy for treatment of prostate carcinoma (Review)
}

\author{
KIFAYAT ULLAH, FRANK ADDAI PEPRAH, FENG YU and HAIFENG SHI \\ Institute of Life Sciences, Jiangsu University, Zhenjiang, Jiangsu 212013, P.R. China
}

Received April 27, 2018; Accepted September 10, 2018

DOI: $10.3892 /$ or.2018.6758

\begin{abstract}
Adoptive cell transfer (ACT) is an emerging immunotherapy technique that restricts tumor growth and invasion in cancer patients. Among the different types of ACT, chimeric antigen receptor (CAR)T-cell therapy is considered to be the most advanced and a potentially powerful technique for the treatment of cancer in clinical trials. The primary aim of CART-cell therapy is to destroy cancer cells and therefore, it serves an important role in tumor immunotherapy. CART-cell therapy has been demonstrated to mainly treat blood cancer by targeting cluster of differentiation (CD)-19, CD20, CD22, CD33 and CD123. However, the use of CART-cell therapy for treating solid tumors is currently under extensive investigation. With respect to prostate cancer, prostatic acid phosphatase, prostate-specific antigen, prostate-specific membrane antigen (PSMA), prostate stem cell antigen, T-cell receptor $\gamma$ alternate reading frame protein, transient receptor potential-p8 and six-transmembrane epithelial antigen of the prostate 1 are among the identified target antigens for prostate tumors. However, mesothelin, fibroblast activation protein, epidermal growth factor receptor, carcinoembryonic antigen, disialoganglioside- 2 and human epidermal growth factor 2 are among the main targets of CART-cell therapy in the case of other types of solid tumors. The main challenges in CART-cell therapy are the selection of the target antigens and the modulation of the ideal tumor microenvironment for T-cells to fight against the cancer. The present review focuses on the 1st, 2nd, 3rd and 4th generations of anti-PSMA CARs and their application for combating prostate carcinoma.
\end{abstract}

Correspondence to: Professor Haifeng Shi, Institute of Life Sciences, Jiangsu University, 301 Xuefu Road, Zhenjiang, Jiangsu 212013, P.R. China

E-mail: shihf@ujs.edu.cn

Key words: prostate specific antigen, chimeric antigen receptors, antigen, T-cell, prostate cancer

\section{Contents}
1. Introduction
2. The CART-cell
3. CAR generations
4. Classified prostate associated antigens
5. CART-cell persistence and trafficking
6. Advantages of the CART-cell
7. Challenges associated with CART-cell therapy
8. Conclusion

\section{Introduction}

Chemotherapy, surgery and radiotherapy are considered to be the most important types of cancer treatments available for patients with solid or hematological malignancies $(1,2)$. Cancer patients are frequently unable to tolerate chemotherapy due to the cytotoxic nature of the drugs. Chemotherapy and radiotherapy are thought to be important in the treatment of cancerous tissues. However, non-cancerous tissues are equally targeted by these therapies $(3,4)$. These treatments are also associated with poor prognosis and survival of cancer patients. Currently, targeting the immune system to fight cancer is thought to be more effective as it is associated with fewer cytotoxic side-effects (5). Immunotherapy is classified as being much safer than chemotherapy and radiotherapy as it targets specific antigens associated with cancer cells and tumors. Therefore immunotherapy, specifically using T-cells, has potential in the field of cell therapy due to the following: i) T-cells have the potential to differentiate between cancerous and non-cancerous cells (6,7); ii) upon activation, T-cells undergo rapid clonal expansions $(8,9)$; iii) T-cells have the ability to maintain therapeutic responses for a longer period of time (10); and iv) T-cells have the ability to target specific antigens at a variety of different sites $(8,11)$, therefore, they are important for the treatment of local and distant metastases.

Prostate cancer is caused by the malignant growth of the cells of the prostate gland, a walnut shaped organ in males located below the bladder and behind the rectum, which produces and stores seminal fluid. The American Cancer Society projects that 164,690 novel cases of prostate cancer will be diagnosed with 29,430 men expected to succumb to this disease in 2018 (12). Prostate cancer has been classified 
as one of the leading causes of mortality among men worldwide $(13,14)$. However, over the past few decades, the mortality rate has stabilized due to early diagnosis, which helps to maintain or cure the disease $(12,15)$.

A broad range of treatment options are available for men diagnosed with prostate cancer, including surgery (prostatectomy), radiation, chemotherapy (drug therapy), high intensity focused ultrasound or through an integrated cancer program (16-18). Another method, which is the subject of the present review, is the application of immunotherapy.

The aforementioned methods of treatment have been widely used, however, they frequently leave the patient with adverse side-effects; therefore, there is a need to develop a more efficient method with fewer side-effects. Immunotherapeutic techniques have now been employed for over a century in the treatment of tumors and in the last few decades have greatly improved and produced effective applications $(19,20)$. Methods including cytokine induced killers, tumor infiltrating lymphocytes, monoclonal antibodies (mAbs), tumor vaccines, immune checkpoint blockades, bispecific antibodies and chimeric antigen receptor (CAR)T-cell are a few of the immunological techniques employed in cancer treatments $(21,22)$. Among the techniques and approaches employed, CART-cell therapy is an advanced method with promising curative potential.

Nonetheless, while the use of CART-cell therapy is advanced in hematological malignancies, it is also presenting potential in solid tumors, though at a limited rate. The delay over the years has been as a result of the difficulty of immune cells targeting and penetrating tumors and cancerous cells, as well as overcoming the metabolically hostile tumor microenvironment $(23,24)$.

\section{The CART-cell}

CAR is an antigen targeting protein receptor engineered to fuse with T-cells and designed to specifically bind to antigens on tumors or cancerous cells that are mostly unrecognized by normal T-cells. The CAR exhibits the following features: i) An antigen binding part; ii) a hinge region; iii) a transmembrane domain; and iv) an intracellular co-stimulatory domain (Fig. 1) (25-27).

The antigen-binding domain is an extracellular single-chain variable fragment ( $\mathrm{scFv}$ ) antibody that specifically recognizes an antigen on the surface of cancerous cells. scFvs are designed from full length $\mathrm{mAbs}$ to reduce the undesirable effects accompanied by the fragment crystallizable domain $(\mathrm{Fc})$ and to increase antigen binding affinity. An scFv fragment consists of variable heavy and light chains joined together by a flexible peptide linker (28). The hydrophilic nature of the linker residue enhances flexibility through its glycine and serine sequences, whereas the interspersed glutamine and lysine sequences enhance solubility $(29,30)$. In normal T-cell receptors (TCRs), the antigen-binding domain is the cluster of differentiation (CD) $3-\zeta$ chain, which recognizes antigen in a major histocompatibility complex (MHC).

The hinge region is a flexible part that directs the $\mathrm{scFv}$ to the target antigen. The transmembrane domain and its associated proteins also serve a critical role in the signal transduction and surface expression of the receptor (31). It has also been demonstrated to provide stability to the CAR and could dimerize to form complexes with endogenous TCRs resulting in enhanced T-cell activation (32).

The intracellular signaling domain, which usually originates from the signal transduction subunit of T-cells or natural killer cells, includes 4-1BB and CD28, and its function is to transduce extracellular binding signals to initiate the activation of downstream signaling cascades. T-cell activation relies on the phosphorylation of immunoreceptor tyrosine-based activation motifs (ITAMs) present in the cytoplasmic CD3- $\zeta$ domain. While the majority of current CAR endo-domains contain an activation domain derived from CD3- $\zeta$, other ITAM-containing domains have been investigated including the Fc receptor of the immunoglobulin $(\mathrm{Ig}) \mathrm{E}-\gamma$ domain, however, this has been demonstrated to be less effective (32).

Modes of T-leucocyte mediated tumor action. The T-lymphocyte mediated immune response serves a major role in adaptive immunity by attacking infected cells or invading the microorganism and memorizing the targeted antigens to protect against subsequent infections $(8,33)$. TCRs bind antigens presented by antigen presenting cells (APCs), which in turn activate the T-cell. The binding of TCRs to the antigen releases cytokines and other inflammatory molecules which help to kill the infected cells or remove the foreign organism $(34,35)$. In the case of cancer, MHCs are downregulated which limits its antigen presenting ability and therefore, cancerous cells and tumors are able to escape the surveillance of T-cells (36).

Production and autologous transfer of CART-cells. The processes involved in the creation of CART-cells, its autologous transfer and monitoring have been described by Porter et al $(37,38)$. To produce CART-cells, CD4 ${ }^{+}$and $\mathrm{CD}^{+}$ $\mathrm{T}$ lymphocytes are separated from the patient or donor's blood through leukapheresis. Isolated T-cells are then transfected with a viral vector including lentivirus, containing genes for CAR. The virus integrates CAR genes into the T-cell genome and expresses the cell surface CAR protein. The genetically modified T-cells are then cultured with a sufficient amount of interleukin (IL)-2 in vitro. Subsequently, autologous CART-cells are injected back into the patient and the patient is then monitored for treatment responses and for the function of the modified T-cells (37-39).

CART-cell antitumor mechanism. Normal T-cell mediated immune responses require the presence of an antigen in an MHC-dependent complex and a co-stimulatory signal, which involves the recruitment of CD28 on the T-cell surface with the co-stimulatory molecule CD80 or CD86 on the APC $(34,35)$. However, activation of CART is independent of MHC. Upon recognition of the cancer antigen by surface CAR scFv, the T-cell is activated by ITAMs, which leads to the subsequent induction of cytotoxic cytokine secretion and T-cell proliferation. The cytotoxic role of the activated CART-cells is initiated through the secretion of perforin and granzyme granules and the activation of death receptor signaling through Fas/FasL and tumor necrosis factor (TNF)/TNF receptor. The enhanced secretion and proliferation of proinflammatory cytokines [IL-2, interferon (IFN)- $\gamma$, IL-12 and TNF] following the activation of CART-cells is critical for targeted cell lysis (22). 


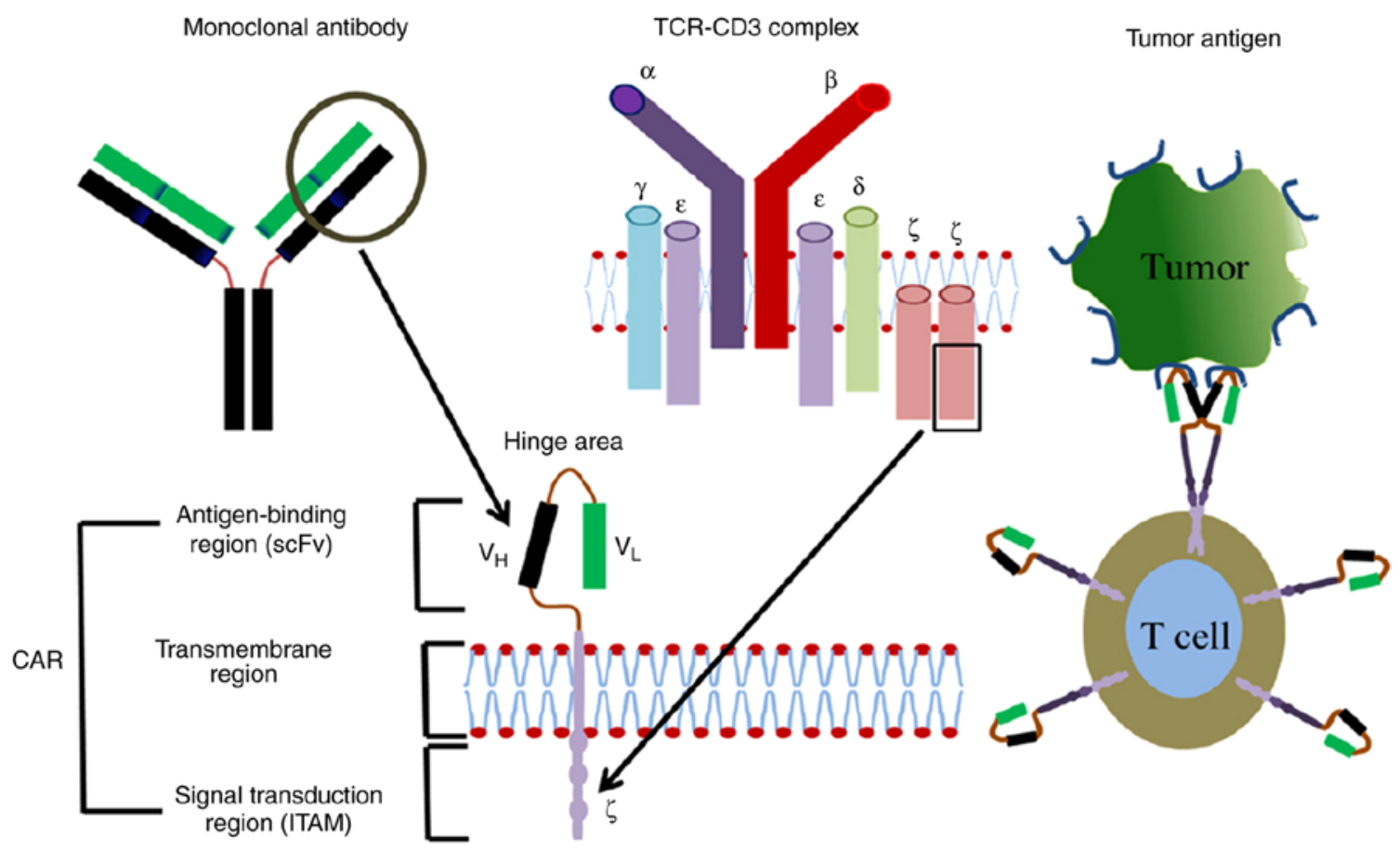

Figure 1. CARs are comprised of a surface antigen-binding region, transmembrane region and intracellular signal transduction region. Derived from a mono-antibody, the antigen-binding region consists of $\mathrm{V}_{\mathrm{H}}$ and $\mathrm{V}_{\mathrm{L}}$ chains, which are joined by a flexible hinge area. Dimer membrane proteins including CD3, CD8 and CD28 are demonstrated in the transmembrane region. The intracellular signal transduction region is comprised of immuno-tyrosine-based activation motifs, including $\mathrm{CD} 3 \zeta$ or FcERly. CARs, chimeric antigen receptors; CD, cluster of differentiation; Fc, fragment crystallizable domain; TCR, T-cell receptor; $\mathrm{V}_{\mathrm{H}}$, variable heavy chain; $\mathrm{V}_{\mathrm{L}}$, variable light chain; ITAM, immunoreceptor tyrosine-based activation motif; scFv, single-chain variable fragment.

\section{CAR generations}

A broader understanding of CAR signaling has led to an improvement in the engineering of various signaling domains that are potent in enhancing the complete activation of T-cells. A total of four generations of CAR are currently under investigation in preclinical and ongoing clinical studies (Fig. 2). These generations are distinguished by their intracellular signaling domains attached to the $\mathrm{scFv}$ receptor molecule. The first-generation CAR has only $\mathrm{CD} 3 \zeta$ as the intracellular signaling domain. However, the second-generation CAR has an additional co-stimulatory domain, which may be CD27, CD28, CD137 (4-1BB) or OX40. The third-generation CAR contains $\mathrm{CD} 3 \zeta$ and two other co-stimulatory domains such as CD28, CD137 (4-1BB) or other co-stimulatory molecules (40-42). To enhance the efficacy of CARs, the T-cells are modulated through the introduction of additional genes, including those encoding potent antitumor cytokines including IL-2 and IL-15 or co-stimulatory ligands including 4-1BBL, thereby generating engineered T-cells that are more potent and cytotoxic to tumors. This is the fourth-generation CAR that is still under investigation to improve the expression of the required cytokines and to control the excessive release of other inflammatory cytokines (7,43-45).

Sipuleucel-T is a treatment option for asymptomatic or minimally symptomatic metastatic castrate-resistant prostate cancer approved by the Food and Drug Administration. This therapy reintroduces activated T-cells specific for the prostatic acid phosphate (PAP) antigen into the patient. Sipuleucel-T consists of autologous peripheral blood mononuclear cells obtained via leukapheresis, which are then cultured and activated with a recombinant human protein consisting of PAP linked to granulocyte-macrophage colony-stimulating factor (46-48). Sipuleucel-T does not require the genetic engineering applied in CART and the activation of T-cells is performed in vitro using the PAP antigen which is highly expressed in prostate cancer (49).

\section{Classified prostate associated antigens}

A few protein and glycoprotein molecules preferentially expressed in malignant prostate tissues, which serve as targets for CART have been described previously. These include PAP, prostate-specific antigen, prostate-specific membrane antigen (PSMA), prostate stem cell antigen (PSCA), T-cell receptor $\gamma$ alternate reading frame protein, transient receptor potential-p8 and six-transmembrane epithelial antigen of the prostate 1 (49).

The PSMA. PSMA is a cell surface glycoprotein expressed in the prostate epithelial cell membrane of normal prostates but is expressed to a substantially higher degree in prostate carcinomas. It contains 750 amino acids, with a type II transmembrane domain similar to that of the transferrin receptor (50). An ELISA performed by Sokollof et al (51), revealed high expression levels of PSMA in prostatic tissues but low expression in the cell membranes of the breast, colon, liver and kidneys with negligible levels of expression on other membranes. Semen content is high in PSMA and therefore, PSMA is observed in high expression levels in prostate epithelial cells. As the PSMA is a membrane-bound antigen with high prostate tissue specificity, it has become a major prostate cancer marker for metastatic castrate-resistant prostate cancer 


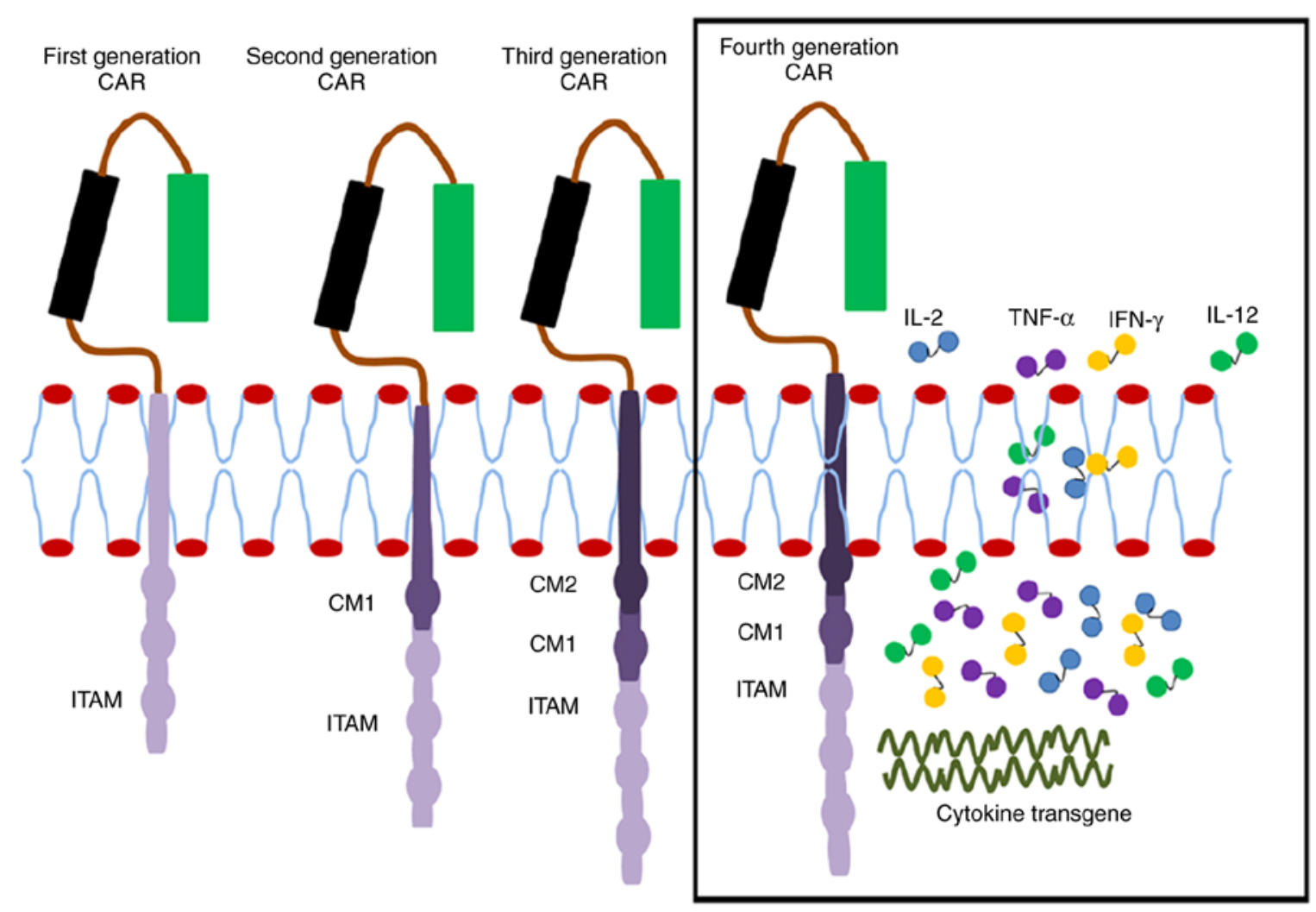

Figure 2. Single chain antibody links with the ITAM (CD24ל or FcERly) of the first-generation CAR forming a transmembrane region. In the second generation, CM1 (including CD28) has been engineered to the signal transduction region. The third generation has another CM2 based on the second generation, combining CD134 or CD137. The fourth generation is further enhanced to produce more cytotoxic cytokines. CAR, chimeric antigen receptor; CD, cluster of differentiation; ITAM, immunoreceptor tyrosine-based activation motif; Fc, fragment crystallizable domain; CM, co-stimulatory molecule; IL, interleukin; TNF- $\alpha$, tumor necrosis factor; IFN, interferon.

and other types of cancer associated with the prostate. PSMA is a promising target for the treatment of metastatic prostate cancer (52), although it is not absolutely specific to prostate tissue (53). Even though PSMA is a promising immunotherapeutic target for metastatic prostate cancer, using it as an exclusive target can lead to different types of autoimmune disorders as other cells also express the surface glycoprotein. The PSCA is also a cell membrane glycoprotein that is highly expressed in the prostate. Its expression is upregulated in cases of prostate tumors. In addition to being highly expressed in the prostate, it is also expressed in the kidneys and urinary bladder as illustrated by Silva et al (53), as well as in the placenta, colon, and stomach $(52,54,55)$. Likewise, exclusive targeting of only the PSCA in the treatment of cancer would also lead to the induction of an autoimmune disorder. Therefore, a careful combinatorial approach that targets PSCA and PSMA is expected to increase prostate cancer targeting and reduce the reactivity against healthy tissues expressing either antigen alone $(55,56)$. Feldmann et al (57) designed a Universal CAR that serves as the effector module activated by a target module, which has specificity for PSCA or PSMA.

CART-cells target PSMA. The application of engineered hybrid antigen receptors on T-cells have been effective in the treatment of a number of hematological types of cancer (37). While engineered CART-cells have seen effective improvements in the treatment of hematological cancer, its application in solid tumors has proven to be difficult.
The impediment surrounding the success of CART-cell therapy against solid tumors may be due to the following factors: i) The lack of a unique tumor-associated antigen in the majority of different types of cancer; ii) inefficient trafficking of CART-cells to tumor sites; iii) heterogeneous expression of the targeted antigen(s) leading to outgrowth of antigen-negative tumor variants; iv) inadequate supply of growth factors (including IL-2); v) the presence of immunosuppressive agents; and vi) the metabolically hostile tumor microenvironment (23).

Targeting prostate tumors using mAbs is a technique that has been employed for years. mAbs have proven valuable in cancer treatment by delivering cytotoxic agents to the cancer cells and PSMA serves as an ideal antigen target in prostate cancer. J591 is noted to be the first IgG mAb developed to target the extracellular domain of PSMA and has been humanized to allow for repeated dosing in patients. Prostate cancer cytotoxicity has been reported to occur when there is a coupling of the J591 mAb with ricin A $(19,49)$.

Buhler et al $(58,59)$ demonstrated that the use of the PSMA x CD3 bispecific diabody to selectively activate PSMA-specific $\mathrm{CD}^{+}$and $\mathrm{CD} 4^{+} \mathrm{T}$-cells and to recruit them to the tumor site produced efficient inhibition of tumor growth in a xenograft model which further revealed the effective elimination of human prostate cancers in in vitro and in vivo trials. Another approach for PSMA-specific targeting is based on engineered T-cells expressing chimeric anti-PSMA immunoglobulin-TCR constructs which has been demonstrated to 
specifically lyse PSMA-expressing prostate cancer cells and retard tumor growth in a mouse xenograft model (60).

\section{CART-cell persistence and trafficking}

The efficacy of T-cell function depends on its ability to be directed to the target site and persist. The survival rate or time period of infused modified T-cells (including CART) determines its efficiency in fighting and killing cancerous tumors. While first-generation CARs have a poor persistence rate, the second and third generations have been demonstrated to exhibit higher persistence rates $(23,61)$. Activation of CAR with two or more co-stimulatory domains has been reported to enhance the persistence of infused CART-cells. The persistence of CART-cells can also be improved through lymphodepleting chemotherapy and conditioning chemotherapy, which removes suppressive cells including myeloid cells and regulatory T-cells. Administration of IL-2 can also help improve the persistence of CART-cells (41). Furthermore, for effective tumor eradication to occur, CART-cells should be able to migrate to tumor sites in large numbers and persist for a long period of time. The homing potential of CART-cells to target sites is called trafficking, an essential requirement for T-cell-tumor eradication. Homing of CART-cells has been observed to be enhanced by transducing T-cells with the chemokine receptor expressing gene IL-8R $\beta$ which recognizes chemokine ligand 1 expressed in melanomas (23).

Immunosuppressive agents. Immunosuppressive agents are cells or molecules that partially or completely prevent immune response. Immune suppression occurs to maintain tolerance to self-cells and prevent the development of autoimmune diseases. Immunosuppressive molecules have been demonstrated to be present in markedly high levels at tumors sites, which shields the tumor from immune surveillance and subsequent attack. Immunosuppressive agents that have been reported to protect tumors include regulatory T-cells (Tregs) $(62,63)$, transforming growth factor- $\beta$ (TGF- $\beta$ ) (64) and myeloid-derived suppressor cells (65), together with other immunosuppressive molecules. To escape immunosuppressive effects, genetic modification to CARs can help improve T-cell resistance to immunosuppression. The incorporation of co-stimulatory molecules including CD28 and inhibitory cytokines into CARs can assist T-cells to become more resistant to Tregs and TGF- $\beta$ as well as other associated immunosuppressive molecules $(24,41,66,67)$.

Individuals with recurrent prostate cancer normally undergo androgen deprivation therapy, a technique, which stimulates and activates the overexpression of a serine/threonine kinase, known as protein kinase B, to regulate cancer cell growth and survival. A combination therapy of androgen deprivation and CART-cell infusion can protect CARs against immunosuppression $(68,69)$. In addition, CART-cells can be further improved to express cytokines such as IL-2, IL-12, TNF- $\alpha$ and IFN $\gamma$ in order to escape immunosuppression (70-72).

\section{Advantages of the CART-cell}

CART-cell MHC-independent recognition of tumor antigens allows for universal application as it can recognize surface antigens including proteins, carbohydrates and glycolipids making it difficult for the target tumor to escape antibody recognition $(32,73,74)$. The CART-cell has a broad range of antigen targeting potential compared with normal T-cells due to its ability to produce large numbers of tumor specific T-cells in a moderately short period of time which gives it an advantage in clinical applications $(37,38,75)$. Furthermore, there is reduced autoimmune and cytotoxic responses when the correct gene is inserted into the T-cell (7).

\section{Challenges associated with CART-cell therapy}

Toxicity of CART-cells. The infusion of CART-cells into cancer patients is associated risks regardless of the number of benefits. CART-cells have been proven to be successful in a number of the clinical trials. However, the majority of the time it also led to expected and unexpected toxicities including cytokine release syndrome (CRS), neurologic toxicity, 'on target/off tumor' recognition, and anaphylaxis (76). CRS has been noted as one of the prevalent adverse effects that arises from CART infusion. The activation of infused autologous CART-cells produces inflammatory cytokines that could produce mild to severe CRS and can be life threatening (77). Clinical features, as noted by Bonifant et al (76) and Lee et al (78), include high fever, malaise, fatigue, myalgia, nausea, anorexia, tachycardia/hypotension, capillary leak, cardiac dysfunction, renal impairment, hepatic failure and disseminated intravascular coagulation.

In addition to CRS, another form of toxicity likely to arise from CART-cell infusion is the 'On-target/off-tumor recognition'. This occurs as the targeted antigen on the tumor may not be restricted only to the tumor cells, but may also be present on certain normal cells (79). Activated CART-cells attacking normal self-cells can lead to autoimmune disease and organ/tissue damage.

Insertional oncogenesis. The primary concern associated with engineered T-cells is the insertion or activation of oncogenes in the host's DNA. CART-cells carry a foreign gene transferred through a viral vector with high efficiency, including lentiviral vectors, adenovirus carrier and adeno-associated virus vectors. Integration of the target gene into T-cells may possibly trigger oncogenesis; however, no insertional oncogenesis has been recorded with respect to CART-cells due to the high efficiency vector delivery. Nevertheless, when the gene is redirected to a different site and does not integrate into the specific site, it could lead to insertional mutagenesis $(76,80)$.

Hostile tumor microenvironment. Another challenge impeding the improvement of CART-cell therapy in tumors involves the hostile microenvironment that surrounds tumors. The presence of immunosuppressive cells and increased inflammatory activity around tumors hinders exposure to T-cell activity. Tumor surroundings are known to harbor substantially high concentrations of reactive oxygen species (ROS), which impedes antitumor function. T-cells co-expressing catalase are hypothesized to perform efficiently in such tumor sites. To confirm this, Ligtenberg et al (81) investigated catalase-CART-cells and reported that catalase reduced the oxidative state of the tumor with less accumulation of ROS. The catalase-CART-cell was also observed to maintain antitumor activity $(23,41,81)$. 


\section{Conclusion}

The present review has demonstrated that compared with normal T-cells and first-generation CART-cells, the second and third-generation CARs have superior antitumor functions, providing immunotherapy against prostate tumors and other target tissue tumors. Recently, CART-cell therapy has greatly improved in the treatment of hematological malignancies; however, developments are still ongoing in targeting tumor-associated antigens for future treatments. Due to the absence of specific antigens associated with tumors, it is essential to design T-cells with more than one CAR as this method will increase the efficiency and reduce the risk of autoimmune associated diseases. More importantly, the use of CART-cell therapy for the treatment of prostate cancer is advantageous compared with surgery, radiotherapy and chemotherapy, as it is associated with fewer cytotoxic effects. Therefore, targeting the immune system with CART-cells may be important in treating prostate cancer.

Even though CART-cell therapy demonstrates immense promise as a potential cure for cancer, this system also has potentially life-threatening complications including CRS and the US FDA has registered safety concerns for its application. Although the FDA has approved a number of CART therapy drugs for certain cases of B-cell lymphoma, a number of life-threatening complication cases have been reported in clinical trials because different CARs and delivery methods elicit different cytotoxic responses. Another challenge researchers face is the Federal common rule that provides guidance on human-subject research with CART-cell therapy, which limits its wide application and development. A detailed discussion on the regulatory policy for this technique is essential for its application in the biomedical industry and scientific community. However this is beyond the scope of this review paper.

\section{Acknowledgements}

Not applicable.

\section{Funding}

The present study was supported by the National Natural Science Foundation of China (grant nos. 31271272 and 31600952), the Jiangsu Natural Science Foundation (grant no. BK20151347) and the Priority Academic Program Development of Jiangsu Higher Education Institutions (PAPD).

\section{Availability of data and materials}

All data generated or analyzed during this study are included in this published article.

\section{Authors' contributions}

HS and FY conceived the study. KU and FAP researched the literature, and draft the manuscript. HS and FY critically revised the article. All authors read and approved the manuscript and agree to be accountable for all aspects of the research in ensuring that the accuracy or integrity of any part of the work are appropriately investigated and resolved.

\section{Ethics approval and consent to participate}

Not applicable.

\section{Patient consent for publication}

Not applicable.

\section{Competing interests}

The authors declare that they have no competing interests.

\section{References}

1. Arruebo M, Vilaboa N, Sáez-Gutierrez B, Lambea J, Tres A, Valladares M and González-Fernández Á: Assessment of the evolution of cancer treatment therapies. Cancers 3: 3279-3330, 2011.

2. Ethun CG, Bilen MA, Jani AB, Maithel SK, Ogan K and Master VA: Frailty and cancer: Implications for oncology surgery, medical oncology, and radiation oncology. CA Cancer J Clin 67: 362-377, 2017

3. Alfarouk KO, Stock C-M, Taylor S, Walsh M, Muddathir AK, Verduzco D, Bashir AH, Mohammed OY, Elhassan GO, Harguindey S, et al: Resistance to cancer chemotherapy: Failure in drug response from ADME to P-gp. Cancer Cell Int 15: 71, 2015.

4. Liu H, Lv L and Yang K: Chemotherapy targeting cancer stem cells. Am J Cancer Res 5: 880-893, 2015.

5. Levitzki A: Targeting the immune system to fight cancer using chemical receptor homing vectors carrying polyinosine/cytosine (PolyIC). Front Oncol 2: 4, 2012.

6. Chen ZY, Ma F, Huang H and He CY: Synthetic immunity to break down the bottleneck of cancer immunotherapy. Sci Bull 60: 977-985, 2015.

7. Smith AJ, Oertle J, Warren D and Prato D: Chimeric antigen receptor (CAR) T cell therapy for malignant cancers: Summary and perspective. J Cell Immunother 2: 59-68, 2016.

8. Alberts B, Johnson A, Lewis J, Raff M, Roberts K and Walter P: Lymphocytes and the cellular basis of adaptive immunity. New York: Garland Science, 2002.

9. Mak TW and Saunders ME: The immune response: Basic and clinical principles. Academic Press 2005.

10. Dembic Z: The cytokines of the immune system: The role of cytokines in disease related to immune response. Academic Press 2015.

11. Pennock ND, White JT, Cross EW, Cheney EE, Tamburini BA and Kedl RM: T cell responses: Naive to memory and everything in between. Adv Physiol Educ 37: 273-283, 2013.

12. Siegel RL, Miller KD and Jemal A: Cancer statistics, 2018. CA Cancer J Clin 68: 7-30, 2018

13. Hassanipour-Azgomi S, Mohammadian-Hafshejani A, Ghoncheh M, Towhidi F, Jamehshorani S and Salehiniya H: Incidence and mortality of prostate cancer and their relationship with the human development index worldwide. Prostate Int 4: 118-124, 2016.

14. Haas GP, Delongchamps N, Brawley OW, Wang CY and de la Roza G: The worldwide epidemiology of prostate cancer: Perspectives from autopsy studies. Can J Urol 15: 3866-3871, 2008.

15. Brawley OW: Trends in prostate cancer in the United States. J Natl Cancer Inst Monogr 2012: 152-156, 2012.

16. Cotter K, Konety B and Ordonez MA: Contemporary management of prostate cancer. F1000Res 5, 2016.

17. Lynch JH, Batuello JT, Crawford ED, Gomella LG, Kaufman J, Petrylak DP and Joel AB: Therapeutic strategies for localized prostate cancer. Rev Urol 3 (Suppl 2): S39-S48, 2001.

18. Mottet N, Bellmunt J, Bolla M, Briers E, Cumberbatch MG, De Santis M, Fossati N, Gross T, Henry AM, Joniau S, et al: EAU-ESTRO-SIOG guidelines on prostate cancer. Part 1: Screening, diagnosis, and local treatment with curative intent. Eur Urol 71: 618-629, 2017.

19. Bander NH, Nanus DM, Milowsky MI, Kostakoglu L, Vallabahajosula S and Goldsmith SJ: Targeted systemic therapy of prostate cancer with a monoclonal antibody to prostate-specific membrane antigen. Semin Oncol 30: 667-676, 2003.

20. Morrissey KM, Yuraszeck T, Li CC,Zhang Y and Kasichayanula S: Immunotherapy and novel combinations in oncology: Current landscape, challenges, and opportunities. Clin Transl Sci 9: 89-104, 2016 
21. Khalil DN, Budhu S, Gasmi B, Zappasodi R, HirschhornCymerman D, Plitt T, De Henau O, Zamarin D, Holmgaard RB, Murphy JT, et al: The new era of cancer immunotherapy: Manipulating T-cell activity to overcome malignancy. Adv Cancer Res 128: 1-68, 2015.

22. Yu S, Li A, Liu Q, Li T, Yuan X, Han X and Wu K: Chimeric antigen receptor $\mathrm{T}$ cells: A novel therapy for solid tumors J Hematol Oncol 10: 78, 2017.

23. Mirzaei HR, Rodriguez A, Shepphird J, Brown CE and Badie B: Chimeric antigen receptors $\mathrm{T}$ cell therapy in solid tumor: Challenges and clinical applications. Front Immunol 8: 1850, 2017.

24. Mohammed S, Sukumaran S, Bajgain P, Watanabe N, Heslop HE, Rooney CM, Brenner MK, Fisher WE, Leen AM and Vera JF: Improving chimeric antigen receptor-modified $\mathrm{T}$ cell function by reversing the immunosuppressive tumor microenvironment of pancreatic cancer. Mol Ther 25: 249-258, 2017.

25. Abate-Daga D and Davila ML: CAR models: Next-generation CAR modifications for enhanced T-cell function. Mol Ther Oncolytics 3: 16014, 2016.

26. Qin L, Lai Y, Zhao R, Wei X, Weng J, Lai P, Li B, Lin S, Wang S, $\mathrm{Wu} \mathrm{Q}$, et al: Incorporation of a hinge domain improves the expansion of chimeric antigen receptor T cells. J Hematol Oncol 10: 68, 2017.

27. Sommermeyer D, Hill T, Shamah SM, Salter AI, Chen Y, Mohler KM and Riddell SR: Fully human CD19-specific chimeric antigen receptors for T-cell therapy. Leukemia 31: 2191-2199, 2017.

28. Monnier PP, Vigouroux RJ and Tassew NG: In vivo applications of single chain $\mathrm{Fv}$ (variable domain) ( $\mathrm{scFv}$ ) fragments. Antibodies 2: 193-208, 2013.

29. Whitlow M, Bell BA, Feng S-L, Filpula D, Hardman KD, Hubert SL, Rollence ML, Wood JF, Schott ME, Milenic DE, et al An improved linker for single-chain Fv with reduced aggregation and enhanced proteolytic stability. Protein Eng 6: 989-995, 1993.

30. Alfthan K, Takkinen K, Sizmann D, Söderlund H and Teeri TT: Properties of a single-chain antibody containing different linker peptides. Protein Eng 8: 725-731, 1995.

31. Zidovetzki R, Rost B and Pecht I: Role of transmembrane domains in the functions of B-and T-cell receptors. Immunol Lett 64: 97-107, 1998.

32. Dotti G, Gottschalk S, Savoldo B and Brenner MK: Design and development of therapies using chimeric antigen receptor-expressing T cells. Immunol Rev 257: 107-126, 2014.

33. Janeway CA Jr, Travers P, Walport $M$ and Shlomchik M: Principles of innate and adaptive immunity immunobiology. Garland Science, New York, 2001

34. Alberts B, Johnson A, Lewis J, Raff M, Roberts K and Walter P Molecular Biology of the Cell. 4th edition. Garland Science, New York, NY, 2002

35. Artyomov MN, Lis M, Devadas S, Davis MM and Chakraborty AK: CD4 and CD8 binding to MHC molecules primarily acts to enhance Lck delivery. Proc Natl Acad Sci USA 107: 16916-16921, 2010

36. Choi YE, Yu HN, Yoon $\mathrm{CH}$ and Bae YS: Tumor-mediated down-regulation of MHC class II in DC development is attributable to the epigenetic control of the CIITA type I promoter. Eur J Immunol 39: 858-868, 2009.

37. Porter DL, Levine BL, Kalos M, Bagg A and June CH: Chimeric antigen receptor-modified $\mathrm{T}$ cells in chronic lymphoid leukemia New Engl J Med 365: 725-733, 2011.

38. Porter DL, Levine BL, Bunin N, Stadtmauer EA, Luger SM, Goldstein S, Loren A, Phillips J, Nasta S, Perl A, et al: A phase 1 trial of donor lymphocyte infusions expanded and activated ex vivo via CD3/CD28 costimulation. Blood 107: 1325-1331, 2006

39. Jacobson CA and Ritz J: Time to put the CAR-T before the horse. Blood 118: 4761-4762, 2011.

40. Cartellieri M, Bachmann M, Feldmann A, Bippes C, Stamova S, Wehner R, Temme A and Schmitz M: Chimeric antigen receptor-engineered $\mathrm{T}$ cells for immunotherapy of cancer. J Biomed Biotechnol 2010: 956304, 2010.

41. Haji-Fatahaliha M, Hosseini M, Akbarian A, Sadreddini S, Jadidi-Niaragh F and Yousefi M: CAR-modified T-cell therapy for cancer: An updated review. Artif Cells Nanomed Biotechnol 44: $1339-1349,2016$.

42. Kulemzin S, Kuznetsova V, Mamonkin M and Taranin A: Engineering chimeric antigen receptors. Acta Naturae 9: 6-14, 2017.

43. Chmielewski M and Abken H: TRUCKs: The fourth generation of CARs. Expert Opin Biol Ther 15: 1145-1154, 2015.
44. Chmielewski M, Kopecky C, Hombach AA and Abken H: IL-12 release by engineered $\mathrm{T}$ cells expressing chimeric antigen receptors can effectively Muster an antigen-independent macrophage response on tumor cells that have shut down tumor antigen expression. Cancer Res 71: 5697-5706, 2011.

45. Scarfò I and Maus MV: Current approaches to increase CAR $\mathrm{T}$ cell potency in solid tumors: Targeting the tumor microenvironment. J Immunother Cancer 5: 28, 2017.

46. Anassi E and Ndefo UA: Sipuleucel-T (provenge) injection: The first immunotherapy agent (vaccine) for hormone-refractory prostate cancer. P T 36: 197-202, 2011.

47. Westdorp H, Sköld AE, Snijer BA, Franik S, Mulder SF, Major PP, Foley R, Gerritsen WR and de Vries IJM: Immunotherapy for prostate cancer: Lessons from responses to tumor-associated antigens. Front Immunol 5: 191, 2014.

48. Ge C, Li R, Song X and Qin S: Advances in evidence-based cancer adoptive cell therapy. Chin Clin Oncol 6: 18, 2017.

49. Kiessling A, Wehner R, Füssel S, Bachmann M, Wirth MP and Schmitz M: Tumor-associated antigens for specific immunotherapy of prostate cancer. Cancers 4: 193-217, 2012.

50. Murphy GP, Greene TG, Tino WT, Boynton AL and Holmes EH: Isolation and characterization of monoclonal antibodies specific for the extracellular domain of prostate specific membrane antigen. J Urol 160: 2396-2401, 1998.

51. Sokoloff RL, Norton KC, Gasior CL, Marker KM and Grauer LS: A dual-monoclonal sandwich assay for prostate-specific membrane antigen: Levels in tissues, seminal fluid and urine. Prostate 43: 150-157, 2000.

52. Saeki N, Gu J, Yoshida T and Wu X: Prostate stem cell antigen: A Jekyll and Hyde molecule? Clin Cancer Res 16: 3533-3538, 2010.

53. Silver DA, Pellicer I, Fair WR, Heston W and Cordon-Cardo C: Prostate-specific membrane antigen expression in normal and malignant human tissues. Clin Cancer Res 3: 81-85, 1997.

54. NCBI: PSCA prostate stem cell antigen. NCBI 2010.

55. Kloss CC, Condomines M, Cartellieri M, Bachmann M and Sadelain M: Combinatorial antigen recognition with balanced signaling promotes selective tumor eradication by engineered T cells. Nat Biotechnol 31: 71-75, 2013.

56. Duong CP, Westwood JA, Berry LJ, Darcy PK and Kershaw MH: Enhancing the specificity of T-cell cultures for adoptive immunotherapy of cancer. Immunotherapy 3: 33-48, 2011.

57. Feldmann A, Arndt C, Bergmann R, Loff S, Cartellieri M, Bachmann D, Aliperta R, Hetzenecker M, Ludwig F, Albert S, et al: Retargeting of T lymphocytes to PSCA- or PSMA positive prostate cancer cells using the novel modular chimeric antigen receptor platform technology 'UniCAR'. Oncotarget 8: 31368-31385, 2017.

58. Bühler P,MolnarE,DopferEP,WolfP,GierschnerD, Wetterauer U, Schamel WW and Elsässer-Beile U: Target-dependent T-cell activation by coligation with a PSMA x CD3 diabody induces lysis of prostate cancer cells. J Immunother 32: 565-573, 2009.

59. Bühler P, Wolf P, Gierschner D, Schaber I, Katzenwadel A, Schultze-Seemann W, Wetterauer U, Tacke M, Swamy M, Schamel W, et al: A bispecific diabody directed against prostate-specific membrane antigen and CD3 induces T-cell mediated lysis of prostate cancer cells. Cancer Immunol, Immunother 57: 43-52, 2008.

60. Ma Q, Safar M, Holmes E, Wang Y, Boynton AL and Junghans RP: Anti-prostate specific membrane antigen designer $\mathrm{T}$ cells for prostate cancer therapy. Prostate 61: 12-25, 2004.

61. Dai H, Wang Y, Lu X and Han W: Chimeric antigen receptors modified T-cells for cancer therapy. J Natl Cancer Inst 108: djv439, 2016.

62. Kiniwa Y, Miyahara Y, Wang HY, Peng W, Peng G, Wheeler TM Thompson TC, Old LJ and Wang RF: $\mathrm{CD}^{+}{ }^{+}$Foxp $^{+}$regulatory $\mathrm{T}$ cells mediate immunosuppression in prostate cancer. Clin Cancer Res 13: 6947-6958, 2007.

63. Vergati M, Cereda V, Madan RA, Gulley JL, Huen NY, Rogers CJ, Hance KW, Arlen PM, Schlom J and Tsangsa KY: Analysis of circulating regulatory $\mathrm{T}$ cells in patients with metastatic prostate cancer pre- versus post-vaccination. Cancer Immunol Immunother 60: 197-206, 2011.

64. Cao Z and Kyprianou N: Mechanisms navigating the TGF- $\beta$ pathway in prostate cancer. Asian J Urol 2: 11-18, 2015.

65. Lopez-Bujanda Z and Drake CG: Myeloid-derived cells in prostate cancer progression: Phenotype and prospective therapies. J Leukocyte Biol 102: 393-406, 2017.

66. Koehler H, Kofler D, Hombach A and Abken H: CD28 costimulation overcomes transforming growth factor- $\beta$-mediated repression of proliferation of redirected human $\mathrm{CD}^{+}$and $\mathrm{CD} 8^{+} \mathrm{T}$ cells in an antitumor cell attack. Cancer Res 67: 2265-2273, 2007. 
67. Loskog A, Giandomenico V, Rossig C, Pule M, Dotti G and Brenner M: Addition of the CD28 signaling domain to chimeric T-cell receptors enhances chimeric T-cell resistance to T regulatory cells. Leukemia 20: 1819-1828, 2006.

68. Ha S, Ruoff R, Kahoud N, Franke TF and Logan SK: Androgen receptor levels are upregulated by Akt in prostate cancer. Endocr Relat Cancer 18: 245-255, 2011.

69. Mikhailova M, Wang Y, Bedolla R, Lu XH, Kreisberg JI and Ghosh PM: AKT regulates androgen receptor-dependent growth and PSA expression in prostate cancer. Adv Exp Med Biol 617: 397-405, 2008

70. Gosmann C, Frazer IH, Mattarollo SR and Blumenthal A: IL-18, but not IL-12, induces production of IFN- $\gamma$ in the immunosuppressive environment of HPV16 E7 transgenic hyperplastic skin. J Invest Dermatol 134: 2562-2569, 2014.

71. Jiang T, Zhou C and Ren S: Role of IL-2 in cancer immunotherapy. Oncoimmunology 5: e1163462, 2016.

72. Zhao J, Zhao J and Perlman S: Differential effects of IL-12 on Tregs and non-Treg T cells: Roles of IFN- $\gamma$, IL-2 and IL-2R. PLoS One 7: e46241, 2012.

73. Rivière I and Sadelain M: Chimeric antigen receptors: A cell and gene therapy perspective. Mol Ther 25: 1117-1124, 2017.

74. Sadelain M, Brentjens R and Rivière I: The basic principles of chimeric antigen receptor (CAR) design. Cancer Discov 3: 388-398, 2013.
75. Zhang C, Liu J, Zhong JF and Zhang X: Engineering CAR-T cells. Biomark Res 5: 22, 2017.

76. Bonifant CL, Jackson HJ, Brentjens RJ and Curran KJ: Toxicity and management in CAR T-cell therapy. Mol Ther Oncolytics 3: $16011,2016$.

77. GruppSA,Kalos M, BarrettD,AplencR,Porter DL, Rheingold SR, Teachey DT, Chew A, Hauck B, Wright JF, et al: Chimeric antigen receptor-modified T cells for acute lymphoid leukemia. New Engl J Med 368: 1509-1518, 2013.

78. Lee DW, Gardner R, Porter DL, Louis CU, Ahmed N, Jensen M, Grupp SA and Mackall CL: Current concepts in the diagnosis and management of cytokine release syndrome. Blood 124: 188-195, 2014.

79. Curran KJ, Pegram HJ and Brentjens RJ: Chimeric antigen receptors for $\mathrm{T}$ cell immunotherapy: Current understanding and future directions. J Gene Med 14: 405-415, 2012.

80. Tey SK: Adoptive T-cell therapy: Adverse events and safety switches. Clin Transl Immunol 3: e17, 2014.

81. Ligtenberg MA, Mougiakakos D, Mukhopadhyay M, Witt K, Lladser A, Chmielewski M, Riet T, Abken H and Kiessling R: Coexpressed catalase protects chimeric antigen receptor-redirected t cells as well as bystander cells from oxidative stress-induced loss of antitumor activity. J Immunol 196: 759-766, 2016. 